\title{
Card-Contingent Discounts As Sources Of Customer Satisfaction And Dissatisfaction: An Exploratory Inquiry
}

Erhard K. Valentin, (Email: evalentin@weber.edu), Weber State University Anthony Allred, (Email: aallred@weber.edu), Weber State University

\begin{abstract}
The reported exploratory study was undertaken to illuminate the effects of card-contingent discounts $(C C D s)$ on customer satisfaction and dissatisfaction. CCDs are price reductions on certain items that are given only to customers who present a card issued by the seller. Results from our survey of 953 grocery store patrons indicate that shoppers tend to frame CCDs as price reductions to which they are entitled; denying discounts is judged unfair. Typical customers are content, rather than delighted, when CCDs are granted and are disappointed or annoyed when CCDs are witheld. CCDs, therefore, seem more likely to engender dissatisfaction than enhance satisfaction.
\end{abstract}

\subsection{Introduction}

ompetition for customers is intense in most lines of retailing. Staples, the office supply chain, Wild Oats Markets, and Smith's Food and Drug Centers are among the merchants that have tried using card-contingent discounts (CCDs) to increase market share (Bell 1993; Wild Oats Markets 1999). CCDs are price reductions offered on certain items only to customers who present the requisite discount card, which is issued by the seller. Typically, customers apply for discount cards by filling out short forms that ask for the applicant's name, address, and moderate amounts of innocuous additional information. No applicant is refused a discount card, and every applicant is entitled to CCDs immediately upon completing the application form.

The Smith's Food and Drug chain, for example, perpetually advertises "Fresh-Values prices," which apply to an ever changing array of goods. Customers who show cashiers a Smith's Fresh Values Card are charged discounted FreshValues prices while other patrons must pay higher regular prices. Patrons who forget to bring their Fresh Values Cards can apply for new cards, which qualifies them for Fresh-Values prices instantaneously. Or, they can obtain Fresh-Values prices retroactively by returning with a Fresh Values Card and their receipts.

Several interrelated bodies of research, which are cited in the next section, suggest that CCDs are more likely to engender dissatisfaction than enhance satisfaction. This article reports results from a survey of 953 grocery shoppers that probed into the Smith's Fresh-Values Card as a source of customer satisfaction and dissatisfaction. Further, the study examined grocery shoppers' perceptions of CCD prices and their emotional reactions to being awarded or being denied a CCD. Findings contain valuable implications for retailing management and further research.

\subsection{Conceptual Underpinnings}

Oliver $(1997,2000)$ refers to satisfaction and dissatisfaction as comparator responses - i.e., responses triggered by comparisons between outcomes and reference points, such as performance expectations, needs, aspirations, norms, imagined outcomes of options not chosen, and perceptions of equity. Moreover, he distinguishes between comparative performance and nonperformance differences. Performance differences include discrepancies between actual and

Readers with comments or questions are encouraged to contact the authors via email. 
expected prices and between experienced and expected quality. Nonperformance differences include discrepancies between actual prices and adjudged fair prices. In Oliver's (2000) model, both perceived performance and nonperformance differences affect satisfaction and dissatisfaction directly and indirectly via emotions. For instance, desirable, or positive, differences are likely to evoke delight and praise, which enhance satisfaction and, often, customer loyalty. In contrast, undesirable, or negative, differences frequently spawn disappointment, blame, and anger. Further, they commonly effectuate dissatisfaction and customer defection.

The extent to which customers heap praise or blame on merchants depends substantially on the extent to which patrons attribute shopping outcomes to the seller rather than themselves (Oliver 2000). A human tendency is to take credit for favorable outcomes and to blame others for unfavorable results (Fiske and Taylor 1991; Folkes 1988). Thus, customers who forfeit CCDs because they forgot their cards may blame vendors for opportunity losses rather than themselves. In lieu of taking responsibility for their forgetfulness, they may blame merchants for imposing unreasonable or unjust requirements. But regardless of whether customers blame themselves or the seller, losing a discount is apt to be remembered as a dissatisfactory experience to be avoided in the future, perhaps by avoiding the merchant associated with it.

Vast streams of psychological theory and empirical research B particularly, work on reference-point framing (e.g., Kahneman and Tversky 1984; Puto 1987; Tversky and Kahneman 1981, 1991), prospect theory (e.g., Kahneman and Tversky 1979), and mental accounting (Thaler 1980, 1985) B support Oliver's (2000) satisfaction model. They imply or affirm that customer satisfaction and dissatisfaction, attitudes toward products and vendors, customer loyalty, and brand equity can be affected by differences between actual and expected prices and the perceived fairness of prices (e.g., Campbell 1999; Smith, et al. 1999).

Suppose, for example, that a retailer advertises a "blowout sale" and that the advertisement's wording (rather than mention of specific price reductions) leads shoppers to expect discounts of 20 percent. If shoppers (unexpectedly) get 30 percent discounts, they are apt to be delighted, deem the extra 10 percent a gain, and develop favorable attitudes toward the seller. But if they get 10 percent discounts, they will be disappointed, consider the unrealized portion of the expected discount a loss, and, perhaps, resent the seller (Puto 1987). Some disappointed shoppers may even forego purchasing items at 10 percent off when they would have bought them at regular prices had they expected to pay regular prices all along. While such behavior defies microeconomic precepts of rationality (Kahneman, et al. 1986b), it is perfectly consistent with findings from inquiries into reference-point framing (e.g., Kahneman and Tversky 1984; Levin and Gaeth 1988; Thaler 1985; Tversky and Kahneman 1981, 1986).

In our CCD study, we focused sharply on one expectation-performance comparison: the price expected in relation to the price paid. If a shopper's reference price (i.e., the price framed as the reference point) is the regular price, then prospect theory and Oliver's (2000) aforementioned model imply that receiving a CCD will elicit a positive response, while being denied a CCD will evoke a neutral, rather than a negative, reaction. Moreover, in terms of Herzberg's (1966) two-factor motivation theory, receiving a CCD will be a source of satisfaction while being denied a CCD will not be a source of dissatisfaction. In contrast, if the discounted price is the shopper's reference price, then receiving a CCD will engender a neutral response, while being denied a CCD will trigger a negative reaction $\mathrm{B}$ perhaps, a severe negative reaction. Further, receiving a CCD will not be a source of satisfaction, but being denied a CCD will be a source of dissatisfaction. Discounts expected, but denied, may alienate first-time customers to the point that they never return and offend long-time patrons who believe they deserve more consideration. Positive reactions include praise, delight, and satisfaction; whereas negative reactions include disappointment, blame, anger, dissatisfaction, and withdrawal (i.e., shopping elsewhere).

Seemingly, the danger that shoppers' reference prices will approach discounted prices increases to the extent that patrons are accustomed to receiving advertised discounts automatically without presenting a card or the like and to the extent that customers are cognizant of discounts (Nisbett and Ross 1980). In the surveyed metropolitan area, Smith's competitors granted advertised discounts without requiring cards; moreover, Smith's always displayed Fresh-Values prices prominently on shelves so that shoppers were apprised repeatedly of differences between Fresh-Values and regular 
prices. Further, Smith's checkers were required to ask customers for Fresh Values Cards, which tended to remind patrons who did not have Cards that they may have lost discounts.

Customers who lose discounts initially, but recover them by applying for a new Fresh Values Card or by returning later with their receipts and a Card, are unlikely to be as satisfied as customers who receive discounts directly. After all, reclaiming discounts requires extra effort; and dissatisfaction provoked by the initial loss is apt to outweigh satisfaction realized from the subsequent gain, even though the monetary amounts lost and later recovered are equal (Smith, et al. 1999; Thaler 1985).

We also examined one nonperformance comparison, namely actual pricing in relation to perceived equitable pricing. If the discounted price is the reference price, then the difference between the reference and the regular price is tantamount to a surcharge or penalty. Having to pay a penalty tends to be upsetting, per se. But it also may be upsetting because the penalty does not appear evenhanded and, therefore, seems unfair (Oliver 2000; Shaw and Barry 1998). That all patrons can get CCDs simply by applying for a card may be overlooked, or card possession may not be deemed a valid basis for discriminating among patrons. Denying any shopper discount prices may even be viewed as enhancing profits surreptitiously by invoking a technicality to renege on an offer (Kahneman, et al. 1986a, 1986b).

\subsection{Research Questions}

Our research explored CCD programs as sources of satisfaction or dissatisfaction via the Smith's Fresh Values Card. It centered on six broad questions derived largely from Oliver's (2000) model and related prior research cited in the preceding paragraphs. Recall that in Oliver's (2000) model, satisfaction and dissatisfaction have three immediate antecedents: (1) emotional reactions to pertinent stimuli, (2) performance expectations (e.g., about prices), and (3) nonperformance expectations (e.g., about the fairness of pricing). Emotional reactions are affected by performance expectations, nonperformance expectations, and outcome attributions. The general questions that guided our probe into CCDs are:

- Do grocery shoppers favor Smith's CCD program? We asked respondents whether Smith's should get rid of the Fresh Values Card, whether the Card does more harm than good, whether the Card is a nuisance, and whether they and other people would shop more at Smith's if Fresh Values prices were not contingent on showing the Card.

- How do customers respond emotionally to receiving or forfeiting Fresh Values discounts? For example, does receiving a discount make them feel smart or happy? Does forfeiting a discount make them feel stupid or angry?

- What are customers' price expectations? Are patrons' reference prices posted regular prices or Smith's FreshValues prices? Accordingly, do shoppers respond positively to discounts realized and neutrally to discounts forfeited? Or, do they respond neutrally to discounts realized and negatively to discounts forfeited?

- Is Smith's Fresh Values pricing program equitable? For instance, do people think it is fair to charge customers different prices, depending on whether they have a Card or have a Card with them?

- Is satisfaction or dissatisfaction with CCD programs affected by perceived normal practices? For instance, socalled wholesale clubs, such as Sam's Club and Costco, generally require patrons to present membership cards which, in effect, are discount cards. In contrast, few supermarkets require membership cards or other types of discount cards, such as Smith's Fresh Values Card.

- Is satisfaction or dissatisfaction with CCD programs affected by experience? Attitudes toward CCDs may change for better or worse with experience. 


\subsection{Methodology}

\subsection{Questionnaire Design}

Table 1 of the "Results" section lists questionnaire items grouped by topic; however, topics were arrayed differently in the questionnaire to minimize order bias. The listed items reflect the six research questions enumerated heretofore. They served to probe satisfaction and dissatisfaction with the Smith's Fresh Values Card, emotional reactions to Fresh-Values pricing, perceived price performance of the Fresh Values program, perceived equity of Fresh-Values pricing, and differences between shoppers' attitudes toward the Fresh-Values Card and club-membership cards. Respondents also were asked whether they had ever had a Fresh-Values Card and whether the grocery store closest to home is a Smith's. Most items were measured on a 5-point Likert-type scale ranging from "Strongly Disagree" to "Strongly Agree"; two questions asked respondents to estimate percentages (e.g., of groceries bought from Smith's); and the remaining questions asked respondents to choose categories (e.g., male or female).

\subsection{Sampling and Questionnaire Administration}

Data were collected via a self-completion questionnaire from 953 metropolitan residents of northern Utah, U.S.A., where Smith's was the only grocery retailer that offered CCDs. In view of the study's exploratory aims, convenience sampling was used (Lehmann, et al. 1998). Questionnaire administrators were instructed to select qualified respondents, to avoid engaging in conversations with respondents that might bias results, and to ask respondents to read instructions and questions very carefully before replying by circling a number, checking a box, or filling in a blank space. Qualified respondents were defined as persons most responsible for grocery shopping within households whose members did not consist entirely of unmarried students. The mean household size of the sample was 3.47 ; moreover, on average, respondents said they bought 88.6 percent of all groceries for their households.

Questionnaire administrators were encouraged to seek out neighbors and relatives who, as a favor, would complete the rather lengthy questionnaire conscientiously. Drawing a random sample of strangers seemed ill-advised for the purposes of this exploratory study because strangers would be less motivated than neighbors and relatives to help out by taking the time required to complete the questionnaire attentively. Further, attempts to draw a genuine random sample very likely would have failed because the questionnaire was so long that, predictably, many busy shoppers would have refused to participate.

\subsection{Data Analysis}

Data were analyzed primarily by referring to item means that summarize replies from the entire sample and from three constituent patronage segments, identified as "High Patronage," "Medium Patronage," and "Low Patronage." Respondents placed in the High Patronage segment said they bought 50 percent or more of their groceries from Smith's during the past 30 days; respondents in the Medium Patronage segment bought between 49 and 10 percent from Smith's; while respondents in the Low Patronage segment bought less than 10 percent from Smith's. The statistical significance of differences among segment means was assessed using the univariate F-ratios from a discriminant analysis (SPSS).

\subsection{Results}

Table 1 provides a statistical summary of results. Rows correspond to questionnaire items, a few of which appear in a slightly abbreviated form. Items have been sorted into sets that correspond to issues investigated (rather than the order in which they were presented to respondents); moreover, results are reported for the entire sample and for the aforementioned High, Medium, and Low Patronage segments. Columns are labeled as follows: " $\bar{x}$ " and "s," respectively, denote the item mean and standard deviation calculated from the sample or subsample of size "n." 


\section{A B General Indicators of Satisfaction/Dissatisfaction With Fresh-Values Pricing ${ }^{a}$}

1. Smith's Fresh Values Card is a nuisance ${ }^{b}$

2. Smith's should get rid of its Fresh Values Card ${ }^{\mathrm{b}}$.....

4. I would shop more at Smith's if I did NOT need a Fresh Values Card to get Fresh Values prices ${ }^{\mathrm{b}} \ldots . . .$.

5.I think more people would shop at Smith's if they did not need a Fresh Values Card to get Fresh Values discounts ${ }^{\mathrm{b}}$

Total Sample
\begin{tabular}{lll}
$\overline{\mathrm{x}}$ & $\mathrm{s}$ & $\mathrm{n}$ \\
\hline
\end{tabular}

$4.04 \quad 1.21 \quad 953$

$3.94 \quad 1.27 \quad 948$

$3.40 \quad 1.20 \quad 952$

$3.28 \quad 1.41952$

$3.82 \quad 1.24 \quad 952$
High Patronage

$\begin{array}{lll}3.52 & 1.35 & 227\end{array}$

$\begin{array}{lll}3.38 & 1.33 & 224\end{array}$

$\begin{array}{lll}2.92 & 1.14 & 227\end{array}$

$\begin{array}{lll}2.85 & 1.33 & 227\end{array}$

$\begin{array}{lll}3.52 & 1.22 & 227\end{array}$
Medium Patronage Low Patronage

\begin{tabular}{llllllll}
$\overline{\mathrm{x}}$ & $\mathrm{s}$ & $\mathrm{n}$ & $\overline{\mathrm{x}}$ & $\mathrm{s}$ & $\mathrm{n}$ \\
\hline
\end{tabular}

$\begin{array}{llllll}3.97 & 1.20 & 267 & 4.34 & 1.04 & 459\end{array}$

$\begin{array}{llllll}3.88 & 1.26 & 265 & 4.24 & 1.14 & 459\end{array}$

$\begin{array}{llllll}3.42 & 1.20 & 267 & 3.64 & 1.16 & 458\end{array}$

$\begin{array}{lllllll}3.42 & 1.39 & 267 & 3.40 & 1.43 & 458\end{array}$

$\begin{array}{llllll}3.85 & 1.22 & 267 & 3.96 & 1.23 & 458\end{array}$

B B Emotional Reactions to Fresh-Values Pricing ${ }^{a}$

1.I would be angry at Smith's if I could not get Fresh-Values discounts because I left my Card at home..... $3.99 \quad 1.21949$

2.I would be angry at Smith's if I could not get Fresh-Values discounts because I had not applied for a Card $^{\mathrm{b}}$

$3.49 \quad 1.38 \quad 953$

$3.93 \quad 1.20 \quad 225$

$3.97 \quad 1.24 \quad 267$

$\begin{array}{lll}4.03 & 1.20 & 457\end{array}$

3. If the Fresh Values price is $\$ 4$ but you had to pay $\$ 5$ because you did not have a Card, how would you

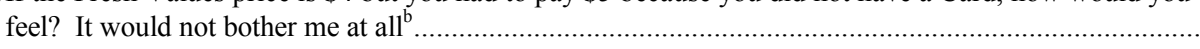

$1.93 \quad 1.25946$

$\begin{array}{lll}3.25 & 1.35 & 227\end{array}$

$\begin{array}{lll}3.49 & 1.42 & 267\end{array}$

$3.61 \quad 1.35 \quad 459$

4. If the Fresh Values price is $\$ 4$ but you had to pay $\$ 5$ because you did not have a Card, how would you feel? I would be upset ${ }^{b}$

$3.90 \quad 1.28 \quad 950$

$2.19 \quad 1.34 \quad 226$

$2.04 \quad 1.29264$

$1.73 \quad 1.15 \quad 456$

5. If the Fresh Values price is $\$ 4$ but you had to pay $\$ 5$ because you did not have a Card, how would you feel? I would feel stupid for shopping at Smith's $\mathrm{s}^{\mathrm{b}}$......

$3.43 \quad 1.43 \quad 951$

$3.71 \quad 1.27 \quad 227$

$3.89 \quad 1.26 \quad 267$

$3.99 \quad 1.30 \quad 456$

6. If the regular price of an item is $\$ 5$ but you paid only $\$ 4$ because you had a Card, how would you feel? I would feel smart for shopping at Smith's ${ }^{\mathrm{b}}$.....

$3.18 \quad 1.28 \quad 953$

$\begin{array}{lll}2.89 & 1.42 \quad 227\end{array}$

$3.37 \quad 1.43 \quad 267$

$3.75 \quad 1.34 \quad 457$

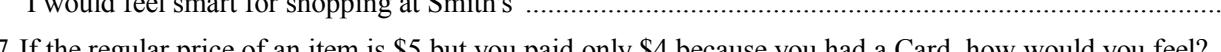

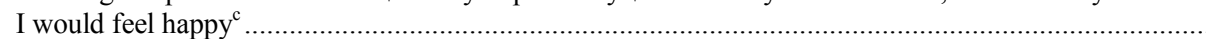

$3.63 \quad 1.16 \quad 227$

$\begin{array}{lll}3.27 & 1.25 \quad 267\end{array}$

$2.90 \quad 1.29 \quad 459$

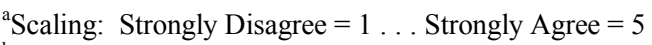

${ }^{b}$ Differences among group means are significant at $p<.001$

${ }^{\mathrm{c}}$ Differences among group means are significant at $\mathrm{p}<.01$ 


\begin{tabular}{|c|c|c|c|c|c|c|c|c|c|c|c|}
\hline \multicolumn{3}{|c|}{ Total Sample } & \multicolumn{3}{|c|}{ High Patronage } & \multicolumn{3}{|c|}{$\begin{array}{l}\text { Medium } \\
\text { Patronage }\end{array}$} & \multicolumn{3}{|c|}{ Low Patronage } \\
\hline $\bar{x}$ & $\mathrm{~s}$ & $\mathrm{n}$ & $\bar{x}$ & $\mathrm{~s}$ & $\mathrm{n}$ & $\bar{x}$ & $\mathrm{~s}$ & $\mathrm{n}$ & $\bar{x}$ & $\mathrm{~s}$ & $\mathrm{n}$ \\
\hline 3.90 & 1.28 & 953 & 3.56 & 1.30 & 227 & 3.96 & 1.16 & 267 & 4.04 & 1.30 & 459 \\
\hline 4.34 & 1.04 & 950 & 4.15 & 1.09 & 227 & 4.27 & 1.10 & 266 & 4.46 & 0.96 & 457 \\
\hline 4.22 & 1.10 & 950 & 3.94 & 1.17 & 226 & 4.14 & 1.19 & 267 & 4.41 & 0.98 & 457 \\
\hline 4.23 & 1.10 & 950 & 3.99 & 1.15 & 226 & 4.11 & 1.19 & 267 & 4.42 & 0.99 & 457 \\
\hline 3.68 & 1.32 & 952 & 3.37 & 1.32 & 227 & 3.61 & 1.38 & 267 & 3.89 & 1.25 & 458 \\
\hline 4.06 & 1.19 & 946 & 3.82 & 1.25 & 227 & 4.00 & 1.21 & 265 & 4.21 & 1.12 & 454 \\
\hline 4.07 & 1.23 & 951 & 3.77 & 1.30 & 226 & 4.04 & 1.30 & 267 & 4.23 & 1.13 & 458 \\
\hline 0.59 & 0.49 & 915 & 0.42 & 0.49 & 221 & 0.54 & 0.50 & 253 & 0.70 & 0.46 & 441 \\
\hline 3.67 & 1.19 & 953 & 3.90 & 1.07 & 227 & 3.72 & 1.15 & 267 & 3.53 & 1.24 & 459 \\
\hline 2.58 & 1.24 & 949 & 2.85 & 1.23 & 226 & 2.70 & 1.27 & 266 & 2.38 & $\mathrm{~s} 1.20$ & 457 \\
\hline 2.78 & 1.27 & 951 & 3.13 & 1.20 & 225 & 2.91 & 1.24 & 267 & 2.53 & 1.27 & 459 \\
\hline 3.12 & 1.31 & 951 & 3.57 & 1.21 & 226 & 3.17 & 1.30 & 266 & 2.87 & 1.31 & 459 \\
\hline 2.35 & 1.20 & 952 & 2.94 & 1.21 & 227 & 2.49 & 1.16 & 267 & 1.97 & 1.07 & 458 \\
\hline 2.81 & 1.25 & 949 & 3.26 & 1.19 & 226 & 2.97 & 1.23 & 266 & 2.49 & 1.21 & 457 \\
\hline 3.97 & 1.03 & 949 & 3.66 & 1.10 & 225 & 3.95 & 0.99 & 266 & 4.14 & 0.98 & 458 \\
\hline
\end{tabular}

${ }^{\mathrm{a}}$ Scaling C1-7 and C9-15: Strongly Disagree $=1 \ldots$ Strongly Agree $=5$

${ }^{\mathrm{b}}$ Differences among group means are significant at $\mathrm{p}<.001$ 


\section{B Perceived Equity of Fresh-Values Pricing ${ }^{a}$}

1.It is perfectly fair to charge customers who do not have Cards more than customers who do have

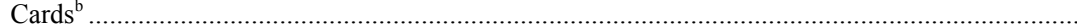

2. It is unfair to charge customers who have Fresh Values Cards less than customers who do not have $\operatorname{Cards}^{\mathrm{b}}$.......

3. If the Fresh Values price is $\$ 4$ but you had to pay $\$ 5$ because you did not have a Card, how would you feel? I would feel I had been treated unfairly ${ }^{\mathrm{b}}$......

4. If the Fresh Values price is $\$ 4$ but you had to pay $\$ 5$ because you did not have a Card, how would you feel? I would feel Smith's treats customers unfairly ${ }^{\mathrm{b}}$

5. Shoppers who have a Card should get Fresh Values prices, even when they forget to bring their

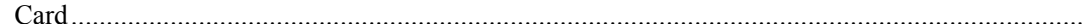

\begin{tabular}{|c|c|c|c|c|c|c|c|c|c|c|c|}
\hline \multicolumn{3}{|c|}{ Total Sample } & \multicolumn{3}{|c|}{ High Patronage } & \multicolumn{3}{|c|}{ Medium Patronage } & \multicolumn{3}{|c|}{ Low Patronage } \\
\hline $\bar{x}$ & $\mathrm{~s}$ & $\mathrm{n}$ & $\bar{x}$ & $\mathrm{~s}$ & $\mathrm{n}$ & $\bar{x}$ & $\mathrm{~s}$ & $\mathrm{n}$ & $\bar{x}$ & $\mathrm{~s}$ & $\mathrm{n}$ \\
\hline 2.18 & 1.41 & 951 & 2.38 & 1.37 & 227 & 2.37 & 1.46 & 265 & 1.97 & 1.37 & 459 \\
\hline 3.66 & 1.33 & 951 & 3.30 & 1.32 & 227 & 3.57 & 1.37 & 266 & 3.90 & 1.27 & 458 \\
\hline 4.00 & 1.21 & 951 & 3.73 & 1.23 & 226 & 3.88 & 1.27 & 267 & 4.19 & 1.12 & 458 \\
\hline 3.81 & 1.27 & 950 & 3.39 & 1.33 & 226 & 3.71 & 1.31 & 266 & 4.07 & 1.15 & 458 \\
\hline 4.09 & 1.17 & 950 & 4.17 & 1.05 & 227 & 4.13 & 1.17 & 265 & 4.03 & 1.23 & 458 \\
\hline
\end{tabular}

\section{E B Smith's Fresh Values Card v. Sam's Club Membership Card ${ }^{a}$}

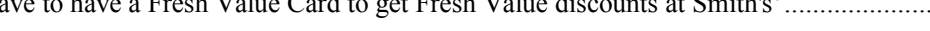

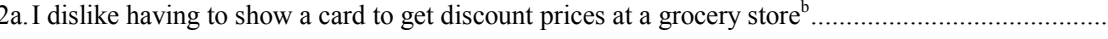

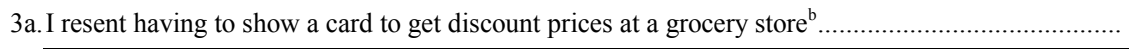

1b. I shouldn't have to have a membership card to buy from Sam's Club.

2b.I dislike having to show a membership card to buy from a store such as Sam's $\mathrm{Club}$

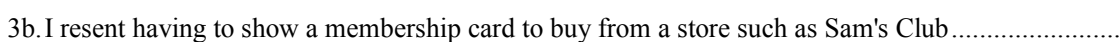

\begin{tabular}{llllllllllll}
4.13 & 1.23 & 951 & 3.79 & 1.29 & 227 & 4.02 & 1.31 & 267 & 4.36 & 1.10 & 457 \\
4.03 & 1.26 & 953 & 3.57 & 1.29 & 227 & 3.90 & 1.37 & 267 & 4.33 & 1.10 & 459 \\
3.68 & 1.41 & 949 & 3.17 & 1.39 & 227 & 3.62 & 1.43 & 265 & 3.96 & 1.33 & 457 \\
\hline 3.52 & 1.33 & 940 & 3.50 & 1.36 & 224 & 3.57 & 1.33 & 260 & 3.50 & 1.32 & 456 \\
3.40 & 1.34 & 933 & 3.33 & 1.36 & 220 & 3.40 & 1.34 & 260 & 3.44 & 1.34 & 453 \\
2.84 & 1.39 & 933 & 2.80 & 1.30 & 220 & 2.90 & 1.41 & 259 & 2.83 & 1.41 & 454
\end{tabular}

F B General Information About Respondents

1. Sex (Male $=0$, Female-1)

Number of people comprising the respondent's household

$0.81-947$

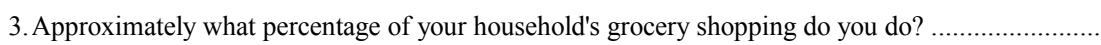

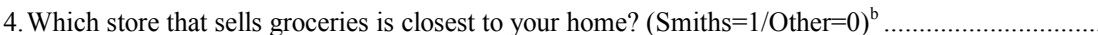

5. Are any other stores that sell groceries almost as close to your home?

(Smith's=1/Not Smith's $=0$ )

6. Have you ever had a Smith=s Fresh Value Card? $(\mathrm{No}=0 \text {, Yes }=1)^{\mathrm{b}}$

$\begin{array}{rrrrrrrrrrrr}0.81 & & 947 & 0.77 & & 227 & 0.78 & 263 & 1.85 & & 457 \\ 3.47 & 1.74 & 950 & 3.30 & 1.78 & 227 & 3.48 & 1.74 & 264 & 3.56 & 1.71 & 459 \\ 88.60 & 17.07 & 950 & 88.08 & 16.59 & 226 & 87.39 & 17.20 & 265 & 89.54 & 17.23 & 458 \\ 0.35 & & 952 & 0.62 & & 227 & 0.40 & & 267 & 0.18 & & 458 \\ 0.31 & & 952 & 0.28 & & 227 & 0.30 & 266 & 0.32 & 459 \\ 0.85 & 0.36 & 948 & 0.98 & 0.13 & 226 & 0.94 & 0.23 & 266 & 0.74 & 0.45 & 456\end{array}$


All items, except C8 and F1 through F6, were measured using 5-point Likert-type scaling. Values for Likertscaled items shown in Table 1 reflect the following coding scheme: Strongly Disagree $=1 \ldots$ Strongly Agree $=5$. Accordingly, $\overline{\mathrm{x}}=3$ indicates, that on average, respondents voiced neutral opinions with regard to the issue in question. Much lower values indicate substantial disagreement, and much higher values indicate substantial agreement.

Item C8 required respondents to indicate whether they thought Smith's Fresh-Values pricing rewards or penalizes shoppers. As shown, 59 percent of the total sample viewed Fresh-Values pricing more as a means of penalizing than rewarding shoppers. Section $\mathrm{F}$ of Table 1, which solicited demographic and some other information, was coded as noted in the table (e.g., male $=0$, female $=1$ ).

\subsection{Discussion}

The following discussions focus on sample means $(\bar{x})$ reported in Sections A through $F$ of Table 1. Again, $\bar{x}<3$ indicates disagreement with a statement, and $\bar{x}>3$ indicates agreement. Implications for retailing management and further research are considered subsequently.

\subsection{General Indicators of Satisfaction and Dissatisfaction (Section A)}

On average, all three patronage segments agreed that Smith's Fresh Values Card is a nuisance and should be scrapped (A1, A2). Moreover, the Medium and Low Patronage segments tended to agree that the Fresh Values Card program does more harm than good (A3) and that they would shop more at Smith's if Cards were not needed to receive Fresh-Values discounts (A4). Even the High Patronage segment opined that more people would shop at Smith's if discounts were not tied to Cards (A5).

In general, the Low Patronage segment agreed most strongly with unfavorable statements about the Fresh Values program and disagreed most strongly with favorable statements. Accordingly, it expressed the least favorable attitudes toward the Fresh Values Card and the Fresh Values program. The High Patronage segment expressed the most favorable attitudes. When presented favorable statements about the Fresh Values program, its mean replies ranged from mild agreement to moderate disagreement. And when presented unfavorable statements, its mean replies ranged from moderate agreement to mild disagreement.

\subsection{Emotional Reactions (Section B)}

Section B summarizes results from items that probed emotional reactions to forfeiting and receiving FreshValues discounts. On average, respondents across all segments agreed they would be angry at Smiths if denied FreshValues discounts because they had left their Cards at home (B1); however, they would be less angry if denied discounts because they had not applied for a Card (B2). Likewise, respondents indicated that being denied the Fresh-Values price for not having a Card would bother and upset them (B3, B4). Only High Patronage customers denied that losing a discount for lack of a Fresh Values Card would make them feel stupid for shopping at Smith's (B5); and only Low Patronage shoppers indicated that getting a discount would not make them feel smart for patronizing Smith's (B6). Receiving a discount for having a Card would make all segments quite happy (B7). However, this finding may reflect attitudes toward discounts in general rather than attitudes toward discounts tied specifically to the Fresh Values Card.

In sum, being denied a Fresh-Values discount appears most distressing to the Low Patronage segment and least upsetting to High Patronage customers. However, High Patronage customers may have responded more favorably than other customers because they have been conditioned to carry their Cards and, therefore, had difficulty imagining being without one. Or, perhaps, frequent patrons get used to losing a discount now and then. Receiving a discount appears to have the least favorable impact on the emotions of infrequent Smith's customers and the greatest favorable impact on steady patrons. 


\subsection{Perceived Price Performance (Section C)}

By and large, means reported for the total sample in Section C suggest that grocery shoppers use prices that approach Fresh-Values prices, not regular prices, as reference points and frame forfeited Fresh-Values discounts as penalties or losses. On average, respondents were inclined to think of Fresh-Values prices as "true" prices and to consider regular prices inflated (C1). They also thought they paid too much if they were denied Fresh-Values discounts (C2). Further, respondents felt that, even if they do not have Cards, they are entitled to Fresh-Values prices (C3-C4) and that customers are virtually robbed or penalized when denied Fresh-Values discounts (C5-C7).

Item C8 seems most useful in sorting out whether shoppers tend to frame differences between regular and FreshValues prices as gains or losses. Rather than being asked to note the extent of their agreement or disagreement with a statement that associates Fresh-Values prices with either a gain or a loss, respondents were given two statements and were asked to choose the one that best describes their feelings toward Fresh-Values prices:

- $\quad$ Smith's Fresh-Values prices reward people who have a Fresh Values Card

- $\quad$ Smith's Fresh-Values prices penalize people who do not have a Fresh Values Card

As shown in Row C8, 59 percent of the total sample chose Statement B, thereby indicating that differentials between regular and Fresh-Values prices were more likely to be perceived, or mentally accounted for, as penalties (losses) than rewards (gains). However, only 42 percent of shoppers in the High Patronage segment associated FreshValues prices more with penalties than rewards.

Items C1-C7 were phrased so that agreement constitutes deeming Fresh-Values prices reference prices and forfeited discounts losses. In contrast, Items C9-C12 were phrased so that agreement constitutes deeming realized discounts gains. Items C7 and C9 indicate that, even though forfeited discounts were considered penalties, realized discounts were deemed rewards. This finding is open to several interpretations and, thus, suggests a topic for further inquiry. Specifically, reference prices may fall between regular and discounted prices; or, reference prices may be contingent on whether a customer has just been denied a discount or given one. Another possibility is that replies do not indicate clearly the mental accounts into which received and forfeited discounts are placed. Instead, replies may reflect little more than recognition of an obvious causal relationship between presenting (not presenting) a Card and getting (not getting) a discount. Nevertheless, the finding that, for the total sample, $\overline{\mathrm{x}}_{\mathrm{C} 7}$ (lost discounts penalize) is substantially greater than $\overline{\mathrm{x}}_{\mathrm{C} 9}$ (obtained discounts reward) intimates that the downside of Fresh-Values pricing (and, perhaps, CCDs in general) is greater than the upside. Congruent with that assessment is the finding that, given a Fresh-Values price of $\$ 4$ and a regular price of $\$ 5$, respondents felt as if a dollar had been stolen from them when charged the higher price (C5), but did not feel as if they had won a dollar when charged the lower price (C10).

Items $\mathrm{C} 11$ and $\mathrm{C} 12$ were intended to probe whether shoppers view Fresh-Values prices as bargain prices. On average, respondents mildly disagreed with the assertion that customers who pay Fresh-Values prices get real bargains (C11); yet, by a very small margin, they agreed that paying a Fresh-Values price of $\$ 4$ for a $\$ 5$ item constitutes a bargain (C12). At best, then, the typical shopper may associate Fresh-Values prices with small bargains that seem unlikely to increase patronage substantially.

Items C13-15 probe further into price performance perceptions. Respondents did not think they would pay less if they bought all of their groceries from Smith's, taking full advantage of Fresh-Values discounts, than they would pay if they bought the same groceries elsewhere (C13). Further, only the High Patronage segment thought that Fresh-Values discounts engendered savings on specific items that would not be matched by Smith's competitors (C14). All segments believed that Smith's raises prices on some goods to compensate for profits lost on discounted items (C15).

\subsection{Perceived Pricing Equity (Section D)}

Analyses of the sample in total, as well as analyses by segment, revealed that shoppers find it unfair to charge 
different prices based on whether customers do or do not present Fresh Values Cards. However, the Low Patronage segment's perceptions of unfairness were most intense.

\subsection{Smith's Fresh Values Card v. Sam's Club Membership Card (Section E)}

Section E addresses whether shoppers' attitudes toward grocery store discount cards, such as Smith's Fresh Values Card, are different from their attitudes toward warehouse club membership cards, such as the Sam's Club Card. Results indicate that having to show a Fresh Values Card or the like is substantially more objectionable than having to show a Sam's Club Card, even though the Sam's Club Card is not free. Moreover, while attitudes toward grocery discount cards vary notably across segments, attitudes toward the Sam's Club Card are nearly invariant.

Attitudinal differences toward the two types of cards may reflect general perceptions of what does and does not constitute normal business practice. Specifically, within the context of warehouse clubs, requiring customers to show cards may be perceived as a normal convention. But within the context of grocery retailing, contrary perceptions and corresponding attitudes may prevail.

\subsection{General Information (Section F)}

Summary statistics reported in Section F profile the sample. Most importantly, proximity information by segment (F4, F5) facilitates understanding perceptual and attitudinal differences among the High, Medium, and Low Patronage segments. These differences are delineated next in terms of their implications for retail management and further research.

\subsection{Implications}

Results from our inquiry into the effects of CCDs on customer satisfaction and dissatisfaction via emotional and cognitive antecedents contain both implications for retailing management and further research. However, our exploratory study was limited to one particular CCD program, Smith's Fresh Values Card; and, as Table 1 indicates, approximately 70 percent of the questions that addressed the Fresh Values Card were framed negatively, which may have biased our findings. Therefore, the delineated implications for retailing management are tentative.

\subsection{Tentative Implications for Retailing Management}

To the extent that the Smith's Fresh Value Card exemplifies CCD programs, our research results suggest that CCDs are more likely to evoke customer dissatisfaction than satisfaction. All three patronage segments B High, Medium, and Low B agreed that the Fresh Values Card is a nuisance, that Smith's should get rid of it, and that more people would shop at Smith's if Fresh-Values discounts were offered without the Card. Further, respondents indicated they would experience emotional distress if denied a Fresh-Values discount, that they view Fresh-Values discounts as no better than those competitors offer routinely without requiring a card, and that denying customers Fresh-Values discounts for not having a Card seems unfair. None of the three patronage segments favored Smith's Fresh Values program. However, the High Patronage segment was more tolerant of the program than the other two segments, especially the Low Patronage segment.

At first glance, response differences among the three patronage segments intimate that whether a household buys a lot or very little from Smith's depends substantially on the main grocery shopper's attitude toward the Fresh-Values program. However, these conclusions must be tempered by results shown in rows F4 and F5. Specifically, 62, 40, and 18 percent of the respondents in the High, Medium, and Low Patronage segments, respectively, reported that the nearest grocery store is a Smith's Food and Drug Center. Further, respectively, 90, 70, and 50 percent said the nearest or almost the nearest grocery outlet is a Smith's store (F4+F5).

These statistics reaffirm what numerous other studies have found, namely that shoppers are inclined to frequent the nearest store, unless they have good reasons for going out of their way (e.g., Reilly 1931; Stanley and Sewall 1978). 
Grocery store patronage decisions, then, may depend much more on spatial convenience than on objections to CCDs. Further, perceptions of CCDs and attitudes toward CCD programs may be mostly consequences of prior patronage decisions B e.g., decisions influenced predominantly by proximity. That frequent Smith's patrons have no unusual inherent tolerance for CCDs, but have learned to accept the Fresh Values Card, is corroborated by the finding that dispositions toward the Sam's Club Card are nearly invariant among the High, Medium, and Low patronage segments (see lines E1b-E3b of Table 1).

The Low Patronage segment is deterred notably by distance from frequenting Smith's, and the Fresh Values Card seems to be an additional deterrent. Infrequent Smith's shoppers may be more attuned to the customs of Smith's competitors and, thus, may react more negatively when asked to produce a Fresh Values Card. Further, even though 74 percent of the Low Patronage segment reported having or having had a Fresh Values Card (F6), Low Patronage shoppers seem less likely than their High Patronage counterparts to have their Fresh Values Cards handy and, thus, seem more highly prone to being denied discounts whenever they do shop at Smith's. Dissatisfying instances of having been denied Fresh-Values discounts may stick in their minds.

In sum, results from our exploratory study intimate rather strongly that Smith's CCD pricing program is illadvised. Even though it may not be a strong deterrent to nearby shoppers, it seems ineffective as a means of attracting customers and cultivating their loyalty. Apparently, Wild Oats Markets (1999) drew similar conclusions from its customer survey and, therefore, abandoned its Wild Shopper CCD program in April 1999.

Smith's and like CCD programs would be defensible if their adverse consequences were more than offset by benefits that could not be gained using innocuous means. For instance, mild negative reactions to CCDs might be acceptable if discount cards provide the most effective means of developing databases that facilitate strengthening retailer-customer bonds. CCDs also might do more good than harm if they engender customer loyalty by providing cumulative incentives and creating switching costs that bind customers as firmly to retailers as so-called frequent-flier miles bind many travelers to particular airlines (Brandenburger and Nalebuff 1995, 1996).

Comparisons between Smith's and Safeway's CCD programs suggest that Smith's program may be more irritating than necessary. Like many video rental stores, Safeway allows discount cardholders to provide a password or telephone number in lieu of presenting a card. Hence, customers who have a card, but do not have it handy, get their discounts without being inconvenienced. Instead of annoying infrequent shoppers, discount cards could be used to attract them. Specifically, shoppers who live closer to competing stores could be mailed card applications and promised 5 or 10 percent discounts the first time they use their cards. Cardholders who did not return regularly could be sent promotional offers aimed to entice them to bypass the nearest store in favor of Smith's.

That CCDs may be better received in some lines of retailing than others is indicated by our finding that, on average, respondents objected much less to the Sam's Club Card than to the Smith's Fresh Values Card. Nevertheless, until more becomes known about CCDs, executives in all lines of retailing seem well advised to approach implementing CCDs with caution. They should ask themselves whether equally effective alternatives are available and, via research into shoppers' perceptions and attitudes, assess the downside risk of particular CCD programs under consideration.

\subsection{Implications for Further Research}

Two questions raised by our study are whether Smith's implementation of CCDs is uniquely ineffective and whether the overall finding that CCDs are more likely to promote dissatisfaction than satisfaction can be generalized to stores other than grocery outlets. Insight into the first question may be gained from replicating our study in markets served by Safeway. Regarding the second question, our exploratory comparisons between attitudes toward the Smith's Fresh Values Card and the Sam's Club Card suggest that shoppers object less to some types of CCD programs than others. One plausible explanation for the difference we observed is that attitudes toward CCDs depend on perceptions of normal business practices: Having to show a membership card to gain entry to a warehouse club was normal within the surveyed metropolitan area, but having to produce a card to receive posted discounts was not the local norm for grocery stores. 
Whether customer acceptance of CCD programs varies geographically is another question that remains to be answered. Again, whether CCDs please or irritate shoppers may depend on the pervasiveness of CD programs within a region or country and also may depend on various cultural factors.

Insights into customers' reactions to CCDs may be gained from delving more deeply into the psychology of price framing and perceptions of fairness when CCDs are offered. Our rudimentary results suggest that reference prices are lower than regular prices, but may not be as low as the prices paid after discounts are applied. Further, shoppers seem inclined to view forfeited discounts as dissatisfying losses and realized discounts as entitlements that enhance satisfaction minimally. Price discrimination policies that are intrinsic to CCDs generally were deemed unfair.

\section{References}

1. Bell, David E. (1993) “Staples, Inc.," HBS-9-593-034, Boston, MA: Harvard Business School Publishing.

2. Brandenburger, Adam M. and Barry J. Nalebuff (1995), "The Right Game: Use Game Theory to Shape Strategy," Harvard Business Review, 73 (July-August), 57-71.

3. Brandenburger, Adam M. and Barry J. Nalebuff (1996), Co-opetition, New York: Currency.

4. Campbell, Margaret C. (1999), "Perceptions of Price Unfairness: Antecedents and Consequences," Journal of Marketing Research, 36 (May), 187-99.

5. Fiske, Susan T. and Shelley E. Taylor (1984), Social Cognition, New York: Random House.

6. Folkes, Valerie S. (1988), "Recent Attribution Research in Consumer Behavior: A Review and New Directions," Journal of Consumer Research, 14 (March), 548-65.

7. Herzberg, Frederick (1966), Work and the Nature of Man. Cleveland, OH: William Collins.

8. Kahneman, Daniel and Amos Tversky (1979), "Prospect Theory: An Analysis of Decision Under Risk," Econometrica, 47 (March), 262-91.

9. Kahneman, Daniel and Amos Tversky (1984), “Choices, Values, and Frames,” American Psychologist, 39 (4), $341-50$.

10. Kahneman, Daniel, Jack L. Knetsch, and Richard H. Thaler (1986a), "Fairness as a Constraint on Profit Seeking: Entitlements in the Market," American Economic Review, 76 (September), 728-41.

11. Kahneman, Daniel, Jack L. Knetsch, and Richard H. Thaler (1986b), "Fairness and the Assumptions of Economics," Journal of Business, 59 (October), S285-300.

12. Lehmann, Donald R., Sunil Gupta, and Joel H. Steckel (1998), Marketing Research. Reading, MA: Addison-Wesley.

13. Levin, Irwin P. and Gary J. Gaeth (1988), "How Consumers Are Affected by the Framing of Attribute Information Before and After Consuming the Product," Journal of Consumer Research, 15 (December), 374-378.

14. Nisbett, Richard and Lee Ross (1980), Human Inference: Strategies and Shortcomings of Social Judgement, Englewood Cliffs, NJ: Prentice-Hall.

15. Oliver, Richard 1. (1997), Satisfaction: A Behavioral Perspective on the Consumer, New York: Irwin/McGraw-Hill.

16. Oliver, Richard L. (2000), "Customer Satisfaction With Service," in Handbook of Services Marketing, Teresa A. Swartz and Dawn Iacobucci, (Eds.), Thousand Oaks, CA: Sage, 247-254.

17. Puto, Christopher P. (1987), “The Framing of Buying Decisions," Journal of Consumer Research, 14 (December), $301-15$.

18. Reilly, William J. (1931) The Law of Retail Gravitation, New York: Knickerbocker Press.

19. Shaw, William H. and Vincent Barry (1998), Moral Issues in Business, Belmont, CA: Wadsworth.

20. Smith, Amy K., Ruth N. Bolton, and Janet Wagner (1999), “A Model of Consumer Satisfaction With Service Encounters Involving Failure and Recovery," 36 (August), 356-72.

21. Stanley, Thomas J. and Murphy A. Sewall (1978), "Predicting Supermarket Trade: Implications for Marketing Management," Journal of Retailing, 54 (Summer), 13-22.

22. Thaler, Richard (1980), "Toward a Positive Theory of Consumer Choice," Journal of Economic Behavior and Organization, 1 (March), 39-60.

23. Thaler, Richard (1985), "Mental Accounting and Consumer Choice," Marketing Science, 4 (Summer), $199-214$.

24. Tversky, Amos and Daniel Kahneman (1981), "The Framing of Decisions and the Psychology of Choice," Science, 211 (January 30), 453-8.

25. Tversky, Amos and Daniel Kahneman (1986), "Rational Choice and the Framing of Decisions," Journal of Business, 59 (October), S251-78.

26. Tversky, Amos and Daniel Kahneman (1991), "Loss Aversion in Riskless Choice: A Reference-Dependent Model," Quarterly Journal of Economics, (November), 1039-61.

27. Wild Oats Markets (1999), “About the Wild Shopper Card,” http:/www.wildoats.com/wildcard. 